\title{
Preparing Surgery House Officers for Their Teaching Role
}

\author{
Kent J. Sheets, PhD, Ann Arbor, Michigan, Fred M. Hankin, MD, Ypsilanti, Michigan,
}

Thomas L. Schwenk, MD, Ann Arbor, Michigan

The medical education literature was reviewed in four categories: (1) general studies of house officer teaching, (2) perceptions of the house officer's teaching role, (3) assessing and improving resident teaching skills, and (4) the teaching role of surgery residents. An agenda for research and development related to surgery resident teaching skills was proposed based on four research questions: (1) What types of teaching skills are most appropriate for surgery residents? (2) How do faculty and student expectations of resident teaching influence surgery resident teaching? (3) What type of intervention is most successful in improving surgery resident teaching skills? (4) What are other outcomes of improved surgery resident teaching besides resident and learner satisfaction? This important teaching role should be more formally and widely acknowledged by surgery faculty, and appropriate teaching skill improvement activities should be provided for all surgery house officers.

\footnotetext{
A fter completion of their medical school education, medical students begin an additional 3 to 7 years of graduate medical education in residency training programs in various specialties of medicine. Resident physicians fulfill major roles in the hospitals and medical schools that administer their residency programs. Their primary role is to provide patient care services under the supervision of faculty and senior house officers. Most of their time is spent in this role. A study by the Institute of

From the Department of Family Practice (KJS) and the Section of Orthopaedic Surgery (TLS), Department of Surgery, University of Michigan Medical School, Ann Arbor, Michigan, and Huron Valley Hand Surgeons (FMH), Y psilanti, Michigan.

Requests for reprints should be addressed to Kent J. Sheets, $\mathrm{PhD}$, Department of Family Practice, University of Michigan Medical School, 1018 Fuller, Ann Arbor, Michigan 48109-0708.

Manuscript submitted September 25, 1989, and accepted in revised form April 3, 1990.
}

Medicine [1] calculated that residents spent $84 \%$ of their time in patient care activities. Concurrently house officers remain students themselves, learning more about their chosen specialty via a combination of conferences, library work, and self-study. In addition to these two primary roles, house officers in all medical specialties are expected, perhaps implicitly, to teach medical students and other house officers. Although this teaching role is an important component of a house officer's daily routine, it is usually an unrecognized and unrewarded component.

Residents in the various surgical specialties are no exception to this situation. They are primarily involved as teachers of medical students and junior residents in their own surgical specialty, but are also called on to teach residents from programs in emergency medicine, other surgical specialties, and family practice. The medical education literature was reviewed to determine how the expectation of this teaching role is translated into actual practice and how medical schools, clinical departments, and surgery residency programs have prepared house officers for this important role.

\section{GENERAL STUDIES OF HOUSE OFFICER TEACHING}

Studies that analyzed house officer and student effort in the hospital setting have documented the amount of teaching done by house officers. Studies published by the Institute of Medicine on costs of education for health professionals in 1974 [2] and on Medicare-Medicaid reimbursement policies in 1976 [1] included information on house officer teaching among their findings. The 1974 study reported that house staff spent 13 of their 60 hours per week in the hospital teaching medical students, junior house officers, and other students. According to this study, residents provided $40 \%$ of the contact medical students had with their instructors. The 1976 study found that residents spent $19 \%$ of their total time in teaching activities, with $90 \%$ of this effort devoted to teaching associated with patient care and $10 \%$ spent in classroom teaching.

The learning experiences of pediatric interns in five different hospitals were assessed by Roghmann et al [3]. The interns identified residents as their most frequent formal teachers; when the teacher categories of interns, residents, and house officer consultants in other specialties were combined, these categories accounted for $48 \%$ of the formal teaching reported by these pediatric interns.

Stefanu et al [4] surveyed house staff at the University of Tennessee College of Medicine and concluded that "the interns, residents, and fellows of most of the clinical departments made a substantial contribution to undergraduate medical education." The authors reported that 
first-, second-, and third-year residents contributed an average of $8.25,9.25$, and 7.00 hours per week, respectively, to undergraduate medical education.

A time study of students and house staff on a medical service at the University of Illinois Hospital was conducted by LaPalio [5]. A workweek of approximately 100 hours was reported. Eight to 10 hours per week were allocated to teaching activities. In an earlier study conducted at the University of Illinois, Schumacher [6] analyzed student clinical activities and concluded that "the major influence of the resident physicians and interns is on the quantity and distribution of conversations between students and house staff."

Patel and Dauphinee [7] investigated characteristics of the clinical learning environment in medicine, pediatric, and surgery clerkships at McGill University in Montreal. The authors determined that residents influence student attitudes and values to a greater extent than faculty and interns because residents spend more time with students. Greenberg and Jewett [8] reported similar findings based on student logs kept during an 8-week third-year pediatric clerkship at Children's Hospital National Medical Center in Washington, D.C. An unanticipated finding of the study was that students rated night call and weekend activities as equally important educationally to activities occurring during weekdays. The authors suggested that the benefits of relating to a resident on a one-to-one basis during these off times might explain this finding.

Studies by Byrne and Cohen [9] and Reichsman et al [10] also noted the contributions of residents to medical student teaching. Schwenk et al [11] stated that interns from four separate family practice residency programs reported nearly $25 \%$ of their educational contact time over the course of a 1-week study was spent with residents as the teachers.

Recent reports have provided summaries of the research on resident teaching. Sheets and Schwenk [12] reviewed in detail the literature on the role of residents as teachers and proposed an agenda for further research and development, while Edwards et al [13] presented detailed examples of research and teaching skill development programs for residents in various specialties and proposed future research on resident teaching. Steward and Feltovich [14] discussed how residents teach, why they can be particularly effective teachers, and how the residents themselves benefit from teaching.

\section{IDENTIFYING PERCEPTIONS OF THE TEACHING ROLE OF THE HOUSE OFFICER}

Several authors have attempted to identify how residents, students, and faculty view the resident's teaching role. Barrow $[15,16]$ described the approach he used as a house officer in internal medicine to develop his own teaching skills and subsequently presented results of a survey of medical student opinions of the house officer as a medical educator. Barrow surveyed graduates of the University of Florida College of Medicine and reported that students estimated that $31 \%$ of the knowledge they gained during clinical clerkships came from residents
(18\%) and interns (13\%) compared with $25 \%$ from attending physicians and $43 \%$ from the students' own initiative.

House staff at the University of Virginia were surveyed by Brown [17] to assess attitudes toward teaching. Residents reported spending $20 \%$ to $25 \%$ of their workweek supervising, evaluating, or teaching others. Interns reported that they spent $10 \%$ of their time on these activities. All the residents and interns considered themselves to be teachers, but less than $10 \%$ had any training as a teacher.

In 1978, the Association of American Medical Colleges (AAMC) surveyed 450 medical school departments to determine faculty practices and experiences evaluating clerks and residents [18]. The three conclusions of this report were: (1) the importance of house officer teaching is not widely translated into a conscious programmatic emphasis; (2) if it is agreed that teaching is an intrinsic component of being a physician, it should be as carefully defined as are clinical responsibilities; and (3) the medical student's perspective is critical in the definition and evaluation of resident teaching.

Tremonti and Biddle [19] studied internal medicine resident and faculty teaching behaviors at three community hospitals affiliated with the State University of New York Upstate Medical Center. Results indicated that in the formal setting, the resident's teaching role was complementary to that of the faculty. Residents were judged to "provide a unique contribution to the education of students, and, therefore, the resident's teaching role should be provided for in settings devoid of house staff."

In 1986, Schiffman [20] described house officers as educators, the benefits of house staff teaching, and strategies to develop and maintain house officer teaching skills. Strategies suggested by the author included faculty role modeling of good teaching skills, teaching skills workshops for residents, and evaluation of resident teaching by students, other residents, and faculty.

Mangione [21] reflected on how medical school did and did not prepare her for residency. Among the topics she discussed was her teaching responsibility as a resident. The author stated that the individuals who made the most difference in her learning on any given clinical rotation were the interns and residents. After addressing the problems inherent in serving as a resident teacher, including an unstructured environment, poorly defined clerkship structure and goals, and an uncertain role as an evaluator of students, the author concluded by recommending that residents should receive formal teacher training and be given concrete objectives by which to evaluate students.

In a survey of 55 internal medicine residents at Northwestern University, Apter et al [22] found that residents enjoyed teaching and considered it a critical aspect of their own education and experience. The authors suggested that resident teaching can be improved by freeing residents from other obligations that interfere with teaching, by increasing faculty observation and guidance of resident teaching, and by careful structuring of resident teaching session content. 


\section{ATTEMPTS TO IMPROVE THE TEACHING SKILLS OF HOUSE OFFICERS}

A number of reports have described efforts to improve and assess the teaching skills of house officers. These reports cover a broad spectrum of medical specialties and educational methods, ranging from half-day workshops to individually designed electives in medical education.

Husted and Hawkins [23] reported in 1963 on a program at the Albany Medical Center and Albany Medical College in which volunteer residents and interns participated in a series of six 1/2-hour seminars on the teaching/ learning process. Although no evaluation methodology was described, the authors described this pilot venture as a success that should be repeated.

Lazerson [24] described a program in the Division of Psychiatry of the Boston University School of Medicine that was designed to prepare psychiatry residents to become better teachers. Developed in conjunction with the School of Education, the program provided residents with a supervised teaching experience in an evening college setting. Lazerson found these experiences to be successful in stimulating the house officer to consider the learning process for the remainder of his/her training.

In 1975, Grimes et al [25] reported on an elective in medical education undertaken by Grimes as an intern in the Department of Obstetrics and Gynecology at the University of North Carolina School of Medicine. His 3month experience permitted him an opportunity to explore the parameters of clinical instruction, suggest strategies to improve clinical instruction, and develop self-instructional materials for use in obstetrics and gynecology.

The House Staff Training Program implemented at the Ohio State University College of Medicine was described in 1976 by Meleca and Schimpfhauser [26]. A needs-assessment survey of 98 residents in medicine, pediatrics, and surgery led to the development of a training program designed to make house staff more effective clinical teachers. Volunteer participants spent approximately 10 hours over a 5 -week period in a series of independent and group study activities. Activities included videotaping and micro-teaching exercises. Although no specific outcomes were described, the program results were termed "most encouraging" by the authors.

Doyle and Balsley [27] reported on a special project at George Washington University Medical Center in which a chief psychiatry resident and her supervisor "adapted traditional clinical supervision to encourage the resident's development as a teacher." In an experience similar to the one undertaken by Grimes [25], the resident worked specifically on improving the case conferences she was responsible for presenting. Both the house officer and clinical supervisor found the experience enjoyable and useful.

A training program designed to improve resident teaching skills was described by Lawson and Harvill [28]. Twenty residents from the Department of Internal Medicine and the Department of Family Practice at the East Tennessee State University College of Medicine participated in 13 weekly 1 -hour small group sessions. The microteaching method was used to provide participants with an opportunity to practice using instructional techniques taught during the sessions. Results indicated that participants made significant gains in teaching performance and attitude toward participation in a teaching skills program. The authors recommended that voluntary house officer participation in similar programs should be strongly encouraged.

Maxmen [29] described an intensive teaching skills program for house officers in the Department of Psychiatric Education at the College of Physicians and Surgeons at Columbia University. Workshops on teaching skills, each 7 hours long, were held on Saturdays in the home of a faculty member. Separate sessions were held for each class of residents to allow for different teaching responsibilities and amounts of teaching. It was reported that nearly $80 \%$ of those residents not on call attended these voluntary workshops. Participants evaluated these experiences favorably.

Jewett et al [30] described a 1-year study conducted at Children's Hospital National Medical Center and George Washington University School of Medicine and Health Sciences. Participating in two half-day workshops on clinical teaching were 27 pediatric house officers, whereas 26 residents received no training until after the study's completion. The study's results indicated that house officers can learn effective clinical teaching skills in a limited amount of time. These results are supported by the fact that faculty, peers, and students consistently gave higher ratings to the teaching of residents who participated in the workshops than to those who had not. In a subsequent report, Greenberg et al [31] presented additional information on how the pediatric residents in the previous report perceived teaching. One of the authors findings was that house officers are ambivalent about teaching as a primary responsibility and reported that medical students made the residents' clinical responsibilities more difficult. However, the residents also reported that teaching improved their clinical and intellectual skills.

A faculty development program for pediatric residents was briefly described by Lewis and Cappelman [32]. Four teaching styles were presented to residents using videotaped examples. After viewing the videotapes, participants were able to appropriately identify the characteristics, strengths, and weaknesses of each style.

In another brief report, Camp et al [33] described a course on teaching for house officers at the Bowman Gray School of Medicine. Four weekly 2-hour sessions were voluntarily attended by 11 third-year residents from the Department of Internal Medicine. All participants reported that the course was valuable and they had thought about new approaches to teaching. Most of the residents reported feeling less anxious about teaching.

Kates and Lesser [34] described a workshop used to prepare psychiatry residents for teaching activities in an 8 -week student clerkship. Four to five simulated vignettes were used to explore various teaching situations that the residents were likely to encounter. No evaluation data were provided.

Observations of residents in internal medicine on work 
rounds at Michael Reese Hospital in Chicago were reported by Wilkerson et al [35]. After the observations, a course on clinical teaching was developed specifically for the residents. Edwards et al [36] reported on a longitudinal study of a resident teaching skills course at the Louisiana State University School of Medicine in New Orleans that showed that resident self-ratings of their teaching skills and satisfaction with the teaching skills course improved over a 2-year period. However, there were not enough data from student ratings for resident teaching skills to be fully interpreted.

\section{THE TEACHING ROLE OF SURGERY RESIDENTS}

Several reports, notably those of Meleca and Schimpfhauser [26] and Patel and Dauphinee [7], have discussed the teaching role of surgery residents as well as residents from other specialties. Other authors have focused strictly on the teaching contributions of surgery residents.

Meleca and Pearsol [37] described a teaching program for surgery residents at the Ohio State University College of Medicine. A 1-day teaching skills seminar was conducted for 66 residents. The content of the seminar included principles of good teaching, effective feedback skills, effective lecture skills, small-group teaching skills, and skills of teaching procedures. The seminar was highly evaluated by the participants on most of the items on the evaluation form used by the investigators.

Brown [38] described a series of eight 90-minute teaching skills seminars for surgery residents at the University of Virginia. Resident performance on cognitive pre- and post-tests showed no significant difference, but $95 \%$ of the participants rated the seminars as a valuable experience.

In 1976, Lowery [39] reported a study designed to determine the significance of house staff teaching in a university department of general surgery. All members of the 1975 graduating class of the University of Utah College of Medicine were administered a questionnaire after their completion of the general surgery clerkship. Students indicated that about a third of the knowledge base they acquired during the general surgery clerkship came from house officer teaching. The data collected from the students indicated little difference in the didactic role of the resident in either the university or community hospital setting.

Holden [40] discussed the quality of surgical clerkships, noting particularly the importance of presenting a professional image to students and the important teaching role played by house officers. "The literature demonstrates unequivocally that surgical house officers, especially the resident in charge of a service, still play a most important role in teaching surgery to medical students." The author suggested that surgical faculty spend time motivating residents and instructing them in the fundamentals of the learning process.

As part of a special report on the clinical education of medical students, Lawrence [4I] provided a perspective from surgical educators. The author discussed the impor- tant contributions that surgeons make to medical education, particularly related to teaching psychomotor skills. His recommendations included rewarding clinical educators with release time and financial benefits for teaching, providing faculty development programs for staff, and directing more effort toward teaching surgical residents how to teach.

\section{COMMENTS}

Several generalizations about surgical resident teaching can be made based on this literature review. It is readily acknowledged that residents are responsible for a large amount of day-to-day teaching of medical students and other house officers. Similarly, it is known that residents greatly influence their students and fulfill a unique teaching role in medical education, one that is complementary to the faculty teaching role. Students enjoy working with residents, often preferring informal, oneon-one contact with house officers to more formal clinical and didactic teaching done by faculty.

Most residents would like to be better teachers, but lack the time (due to heavy clinical responsibilities) to complete the teaching skill development training opportunities traditionally available to faculty. All the different types of interventions described in the review, ranging from brief workshops to multi-session seminars, seem to be both effective and positively received by resident participants. A minimalist approach utilizing a 2- to 3-hour workshop may be optimal due to the high level of participation and benefits gained within a short period of time. Additional programs or consultative services could be provided for residents desiring additional teaching skill development.

In addition to providing a basic level of teaching skills training for house officers, it may be even more important for residency program directors and faculty to acknowledge that teaching is an important component of a resident's daily agenda. Surgery resident teachers should not be asked to learn new complex teaching behaviors, but rather to maximize time spent with students and be enthusiastic and interested teachers and role models. Resident teaching should be monitored by having faculty, students, and junior residents evaluate teaching done by residents. In addition, residents responsible for teaching should be aware of what knowledge, skills, and attitudes students and junior residents are expected to learn during surgery clerkships and rotations. Several questions require further research efforts. Based on these generalizations, an agenda for research and development has been formulated. This agenda is based on a similar agenda proposed by Sheets and Schwenk [12] for all residents in 1988 and is proposed in the context of the following questions.

What types of specific teaching skills are most appropriate for surgery residents? In order to most effectively design and implement programs to improve surgery resident teaching skills, researchers and educators need to know more about the types of teaching skills most frequently used by surgery residents. Do these skills vary from one surgical specialty to another? Do senior 
house officers require different teaching skills than interns? Are different teaching skills required for teaching medical students than are needed for teaching other residents? Are different teaching skills better suited for use by residents in the inpatient than in the outpatient setting?

Past research and development efforts in resident teaching skills have focused on various kinds of teaching skills. The respondents to Brown's survey [17] specifically requested training in instructional methods, public speaking, and evaluation methods. Authors have documented programs that emphasized basic topics such as preparing lectures, teaching skills for teaching and work rounds and hallway discussions, and teaching psychomotor skills [33]; delivery methods, discussion/questioning skills, demonstration techniques and use of audiovisual media, lecturing, and planning instruction [28]; principles of good teaching, effective feedback skills, effective lecture skills, small-group teaching skills, and skills of teaching procedures [37]; and listening to students, questioning students, leading discussions, providing feedback, and informing students [19]. Schwenk and Whitman [42] described in great detail how residents could utilize principles of teaching and learning; prepare lectures, grand rounds, seminars, and journal club presentations; and conduct teaching rounds, morning report, and bedside teaching. Several reports $[19,35]$ have noted that the resident teaching role is complementary to the role fulfilled by faculty. Hankin et al [43] developed a videotape demonstrating examples of three different types of teaching situations frequently encountered by orthopedic surgery residents.

More research is needed to determine which of these skills are most appropriate to the type of teaching performed by surgical residents. Needs-assessment surveys of surgery residents and medical students and intensive observational studies of resident teaching behavior could help identify those skills and behaviors most needed by surgery resident teachers. The authors propose that surgery resident teachers should not be asked to learn new complex teaching behaviors, but rather to continue to spend time with students and be enthusiastic teachers and role models.

How do faculty and student expectations of resident teaching influence surgery resident teaching? There is little evidence in the literature that faculty have been active in encouraging residents to improve as teachers. Tonesk [18] reported that only 87 of the 319 medical school departments who responded to her survey indicated that they evaluated resident teaching performance directly. One example of what can result from faculty interest in resident teaching is documented by Doyle and Balsley [27]. In this instance, a psychiatry faculty provided intensive supervision of the case conferences conducted by a chief resident for an entire academic year. Other than this and other isolated teaching improvement programs for residents, there is little evidence of concentrated faculty support for development of surgical residents as teachers. Research is needed to determine if heightened faculty expectations of resident teaching skills trans- late into improved resident teaching and other positive outcomes. Residency program directors and faculty in surgery should acknowledge that teaching is an important component of a resident's daily agenda. Clerkship and residency program directors should let house officers know what knowledge, attitudes, and skills students and junior residents are expected to learn during clerkships and resident rotations.

Numerous studies have shown that students greatly value the contribution of residents to their education in clinical clerkships. Students surveyed by Byrne and Cohen [9] indicated that the resident was the team member who contributed the most to the student's learning in the clinical clerkship. Greenberg and Jewett [8] noted the students' high assessment of opportunities for one-on-one contact with house officers. Steward and Feltovich [14] identified reasons that residents can be good teachers, including their availability for clinical teaching; their ability to understand better than faculty the practical needs and problems of students; and the students' likelihood of opening up more to residents, asking more questions, and demanding teaching when needed.

Despite these and other reports of how students value the teaching provided by residents, there have been few efforts to let residents know how students feel about them as teachers. Tonesk [18] reported that the "medical student's vantage point is critical to an adequate evaluation of resident instruction, especially since the supervisor's opportunity to observe the teaching is limited." Just as it is imperative that faculty expectations of resident teaching be communicated to residents, student expectations and evaluations of resident teaching must be shared directly with residents. The effects of the combination of student and faculty evaluation of resident teaching should be studied to assess changes in resident teaching behavior and effectiveness.

A combination of faculty and student assessment of resident teaching effectiveness would appear to be the most likely strategy to use to motivate improved surgery resident teaching. Faculty have little or no direct contact with residents who are teaching medical students and junior residents. However, faculty do have some power and authority over residents that can be channeled to motivate them to improve their teaching. Conversely, students have the most contact with residents as teachers, but have no formal means to influence them to be better teachers. Faculty must acknowledge and reward resident teaching as a responsibility of similar importance to patient care and other clinical responsibilities. A combination of student and faculty assessment of resident teaching plus resident self-assessment of teaching should provide a comprehensive assessment of surgery resident teaching that could be used for teaching skill improvement and feedback purposes.

What type of intervention is most successful in improving surgery resident teaching skills? Many different types of educational interventions have been used in programs designed to improve resident teaching skills. Most of the reports have shown varying degrees of success for cach of the types of intervention used. Further re- 
search is needed to determine which of the types of intervention are most successful in terms of cost-effectiveness, efficiency, and eventual adoption by other residency programs and medical schools, but it appears that a minimalist approach utilizing a 2- to 3-hour workshop format may be optimal due to the high level of participation and benefits gained within a short period of time. This approach would guarantee a basic level of teaching skills training for all house officers. One-on-one consultation and additional group sessions could be provided at the request of interested residents.

Studies that compare outcomes of different types of educational methods for improving surgery resident teaching need to be designed and implemented. Most of the research reported in the literature is based on resident and learner satisfaction as measures of the positive outcomes of improved resident teaching. Additional measures such as improved cognitive performance by residents and learners, patient satisfaction, and improved quality of care should be considered as other outcomes to assess resident teaching skill improvement activities. A videotape of effective teaching behaviors used by orthopedic surgery residents [43] can be presented to the residents during regular conference time as a simple intervention and acknowledgment of the importance of resident teaching to the faculty.

What are other outcomes of improved surgery resident teaching besides resident and student satisfaction? Most of the research reported in the literature is based on resident and student satisfaction as measures of the positive outcomes of improved resident teaching. Additional measures such as improved cognitive performance by residents and students, patient satisfaction, and improved quality of care should be considered as other outcomes to assess surgery resident teaching skill improvement activities.

\section{SUMMARY}

The research reviewed in this article demonstrates that all residents play and will continue to play a major teaching role in medical and graduate medical education. Due to the importance of surgical specialties to other surgical and most medical specialties, surgery house officers will be heavily involved in teaching roles with students and residents. This important role should be more formally and widely acknowledged by faculty and administrators, and appropriate teaching skill improvement activities should be provided for all surgery house officers.

This paper makes some important points about the major role that residents play in the education of medical students; their relationship is more than that of a role model.

\section{REFERENCES}

1. Institute of Medicine, Medicare-Medicaid reimbursement policies. Washington, D.C., National Academy of Sciences, 1976.

2. Institute of Medicine. Costs of education in the health professions. Washington, D.C., National Academy of Sciences, 1974.

3. Roghmann K, Pizzo P, Graham E, Graham D, Guyer B, Harris

P. The pediatric internship as a teaching technique: a comparison of learning experiences in five hospitals. Pediatrics 1975; 56: 239-45. 4. Stefanu C, Pate ML, Farmer TA. A management model to survey and analyze house staff effort. J Med Educ 1976; 51: 50-2. 5. I aPalio LR. Time study of students and house staff on a university medical service. J Med Educ 1981; 56: 61-4.

6. Schumacher DN. An analysis of student clinical activities. J Med Educ 1968; 43: 383-7.

7. Patel VL, Dauphinee WD. The clinical learning environments in medicine, pediatrics, and surgery clerkships. Med Educ 1985; 19: 54-60.

8. Greenberg LW, Jewett LS. Student learning on a pediatric clerkship. J Med Educ 1983; 58: 484-6.

9. Byrne N, Cohen R. Observational study of clinical clerkship activities. J Med Educ 1973; 48: 919-27.

10. Reichsman F, Browning FE, Hinshaw JR. Observations of undergraduate clinical teaching in action. $\mathrm{J}$ Med Educ 1964; 39: $147-63$.

11. Schwenk TL, Sheets KJ, Marquez JT, Whitman NA, Davis WE, McClure CL. Where, how, and from whom do family practice residents learn? A multisite analysis. Fam Med 1987; 19: 265-8. 12. Sheets KJ, Schwenk TL. Teaching skill improvement for graduate medical trainees: an agenda for research and development. Eval Health Prof 1988; 11: 3-19.

13. Edwards JC, Plauche WC, Marier RL. Resident teaching: a critical review and future projections. In: Edwards JC, Marier RL, eds. Clinical teaching for medical residents: roles, techniques, and programs. New York: Springer 1988: 228-37.

14. Steward DE, Feltovich PJ. Why residents should teach: the parallel processes of teaching and learning. In: Edwards JC, Marier RL, eds. Clinical teaching for medical residents: roles, techniques, and programs. New York: Springer 1988: 3-14.

15. Barrow MV. The house officer as a medical educator. J Med Educ 1965; 40: 712-4.

16. Barrow MV. Mcdical student opinions of the house officer as a medical educator. J Med Educ 1966; 41: 807-10.

17. Brown RS. House staff attitudes toward teaching. J Med Educ 1970; 45: 156-8.

18. Tonesk $X$. The house officer as teacher: what schools expect and measure. J Med Educ 1979; 54: 613-6.

19. Tremonti LP, Biddle WB. Teaching behaviors of residents and faculty members. J Med Educ 1982; 57: 854-9.

20. Schiffman FJ. The teaching house officer. Yale J Biol Med 1986; 59: 55-61.

21. Mangione $\mathrm{CM}$. How medical school did and did not prepare me for graduate medical education. Clinical education of medical students: a supplement to J Med Educ 1986; 61: 3-10, Part 2.

22. Apter A, Metzger R, Glassroth J. Resident's perceptions of their role as teachers. J Med Educ 1988; 63: 900-5.

23. Husted FL, Hawkins TL. Resident orientation to education: a pilot venture. J Med Fduc 1963; 38: 111-5.

24. Lazerson AM. Training for teaching: psychiatry residents as teachers in an evening college. J Med Educ 1972; 47: 576-8.

25. Grimes DA, Stritter FT, Flair MD, Hendricks $\mathrm{CH}$. A residency elective in medical education. J Med Educ 1975; 50: 365-70. 26. Meleca CB, Schimpfhauser FT. A house staff training program to improve the clinical instruction of medical students. Proc 15th Annual Research in Medical Education Conference. Washington, D.C.: Association of American Medical Colleges, 1976: 267-73.

27. Doyle BB, Balsley E. Supervision of the resident as a teacher. J Med Educ 1979; 54: 338-9.

28. Lawson BK, Harvill LM. The evaluation of a training program for improving residents' teaching skills. J Med Educ 1980; 55: 1000-5.

29. Maxmen JS. The 'teachathon.' J Med Educ 1980; 55: 461-2. 30. Jewett LS, Greenberg LW, Goldberg RM. Teaching residents how to teach. J Med Educ 1982; 57: 361-6.

31. Greenberg LW, Goldberg RM, Jewett LS. Teaching in the clinical setting; factors influencing residents' perceptions, confi- 
dence, and behavior. J Med Educ 1984; 18: 360-5.

32. Lewis JM, Cappelman MM. Teaching style: an introductory course for residents. J Med Educ 1984; 59: 355.

33. Camp MG, Hoban JD, Katz P. A course on teaching for house officers. J Med Educ 1985; 60: 140-2.

34. Kates NS, Lesser AL. The resident as a teacher: a neglected role. Can J Psych 1985; 30: 418-21.

35. Wilkerson L, Lesky L, Medio FJ. The resident as teacher during work rounds. J Med Educ 1986; 61: 823-9.

36. Edwards JC, Kissling GE, Plauche WC, Marier RL. Longterm evaluation of training residents in clinical teaching skills. J Med Educ 1986; 61: 967-70.

37. Meleca CB, Pearsol JA. Teaching surgery residents to teach In: Edwards JC, Marier RL, eds. Clinical teaching for medical residents: roles, techniques, and programs. New York, Springcr
1988: 187-200.

38. Brown RS. Pedagogy for surgical house staff. J Med Educ 1971; 46: 93-5.

39. Lowery SF. The role of house staff in undergraduate surgical education. Surgery 1976; 80: 624-8.

40. Holden WD. The quality of surgical clerkships. Surgery 1985 ; 97: 731-5.

41. Lawrence PF. The clinical education of medical students: a perspective from surgery. Clinical education of medical students: a supplement to J Med Educ 1986; 61: 67-74, Part 2.

42. Schwenk TL, Whitman NA. Residents as teachers: a guide to education practice. Salt Lake City: University of Utah School of Medicine, 1984.

43. American Academy of Orthopaedic Surgeons: Orthopaedic surgery residents as teachers. Videotape \#314, 1989. 